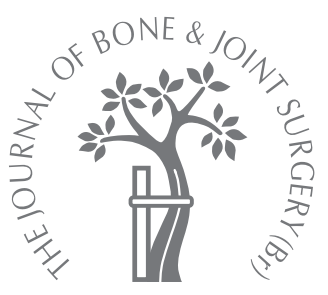

E. Tayton,

S. Evans,

D. O’Doherty

From Cardiff School

of Engineering,

Cardiff University,

Cardiff, United

Kingdom

\title{
Mapping the strain distribution on the proximal femur with titanium and flexible- stemmed implants using digital image correlation
}

\begin{abstract}
We implanted titanium and carbon fibre-reinforced plastic (CFRP) femoral prostheses of the same dimensions into five prosthetic femora. An abductor jig was attached and a 1 kN load applied. This was repeated with five control femora. Digital image correlation was used to give a detailed two-dimensional strain map of the medial cortex of the proximal femur. Both implants caused stress shielding around the calcar. Distally, the titanium implant showed stress shielding, whereas the CFRP prosthesis did not produce a strain pattern which was statistically different from the controls. There was a reduction in strain beyond the tip of both the implants.

This investigation indicates that use of the CFRP stem should avoid stress shielding in total hip replacement.
\end{abstract}

Stress shielding is a reduction in the stresses in a bone caused by an adjacent load-carrying implant, and can lead to subsequent reduction in surrounding bone density owing to lack of a stimulus for the bone to remodel..$^{1}$ It is most clinically relevant in hip replacement, affecting up to $25 \%$ of femora with an uncemented implant but it has also been shown to occur in other areas as well. $^{2,3}$ Extensive laboratory-based investigations have been performed comparing different hip implants in an attempt to find a way to minimise this effect, in order to develop an ideal prosthesis for long-term implantation. Most studies indicate that the stiffer the implant, whether due to shape, thickness or constituent material, the more pronounced the stress shielding. ${ }^{4-7}$ 'Isoelastic' prostheses have therefore been developed in which the implant's stiffness is close to that of bone. ${ }^{8}$

The Bradley implant is a flexible, carbon fibre-reinforced plastic prosthesis with a short titanium insert that forms the trunion (Fig. 1). It is uncemented and has a proximal coating of hydroxyapatite. It has been used in clinical trials since 1990 and a cohort of approximately 150 patients is currently being followed up, but as yet there are no published data regarding the outcome.

Various techniques of measuring the strain experienced by the proximal femur when implanted with different prostheses have been described in the literature. These include the use of surface strain gauges, ${ }^{4-7}$ photoelastic techniques ${ }^{9}$ and finite element modelling. ${ }^{10}$
Digital image correlation (DIC) has been used fairly extensively in engineering, especially in micro- and nano-scale mechanical testing, ${ }^{11}$ but its use in orthopaedics has been limited. It can produce extremely accurate twodimensional (2D) surface strain maps of the area of interest, and provides extensive data allowing accurate statistical analysis between data sets. ${ }^{12}$ The purpose of this study was to compare the stress shielding of a novel flexible implant with a titanium implant of the same dimensions.

\section{Methods}

The experimental work was undertaken in the School of Engineering at Cardiff University. All implantations, procedures and measurements were performed by one investigator (ET). We obtained ten fourth-generation medium composite femora from Sawbones Europe $\mathrm{AB}$ (Malmö, Sweden). These have been independently tested and shown to behave in a biomechanically similar way to human cadaver femora. ${ }^{13}$

We acquired two femoral stems of the same dimensions from Orthodynamics Ltd (Christchurch, Dorset, United Kingdom) (Fig. 1). One consisted of high-strength titanium alloy and the other was a Bradley implant with a carbon-fibre-reinforced plastic (CFRP) stem and a proximal titanium insert. Five of the composite femora were prepared to accommodate the prostheses. Each implant fitted tightly into the prepared femur, with no 


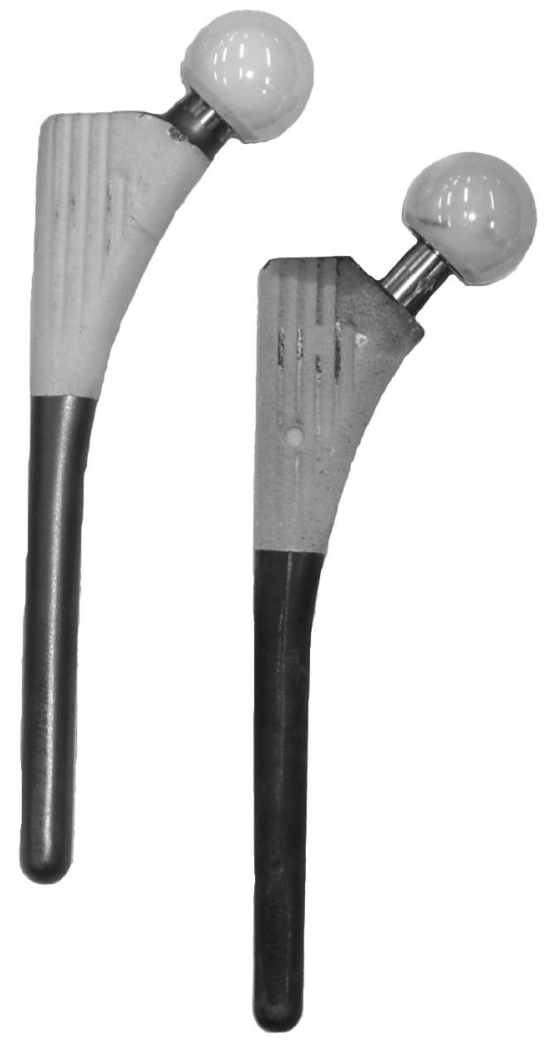

Fig. 1

Photograph of the titanium implant (left) and carbon-fibre reinforced plastic implant (right).

macro-movement evident when a compressive force was applied. Owing to the sturdy nature of the composite bones compared to real bone, the implants were interchangeable in each femur without damage, and with a tight fit obtained each time. A $28 \mathrm{~mm}$ ceramic head was applied to the implants for testing.

A testing rig that grossly simulated a hemipelvis, similar to those described in the literature, ${ }^{5,7,14}$ was created in order to transfer a load from a servohydraulic testing machine (Losenhausen, Dusseldorf, Germany) with an MTS FlexTest GT controller (MTS Systems, Eden Prairie, Minnesota) to the implanted femur and to simulate the abductor muscles (Fig. 2). It consisted of a metal plate with an acetabular component attached to its undersurface so that an articulation could be made with the femoral head. A $40 \mathrm{~mm}$ wide nylon strap was attached proximally to the lateral side of the plate, and distally to the greater trochanter and lateral cortex of the femur, via six small cancellous screws. The plate was attached medially to the compressive device and was supported on the femoral head. The load axis was perpendicular to a line from the centre of the femoral head to the piriform fossa in an attempt to avoid a torsional force acting on the proximal femur when the plate was loaded. The centre of the acetabular component containing the femoral head was positioned $110 \mathrm{~mm}$ lateral to the load axis, and the trochanteric strap was attached to the metal plate $220 \mathrm{~mm}$ lateral to this axis. Hence the plate acted as a lever arm, and when a $1000 \mathrm{~N}$ load was applied a tensile force of $1075 \mathrm{~N}$ was created by the abductor strap. The femur was supported on a ball-bearing distally so that it was held in $12^{\circ}$ of valgus and $10^{\circ}$ of flexion, but could rotate freely. Hence when a vertical force was applied to the head of the femur, the forces and moments created were similar to those of an adult standing on one leg. ${ }^{15}$ The same method was used to test the control femora, but a larger acetabular component was used that could accommodate the anatomical femoral head. This component was lined with a $6 \mathrm{~mm}$ thick insert of 75 durometer Sorbothane rubber in an attempt to mimic the presence of articular cartilage in the true acetabulum.

The digital image equipment was then set up such that two digital cameras (Limess, Pforzheim, Germany) could view the medial cortex of the femora from different directions. They were plugged into the computer and the system was calibrated using a grid target and Vic3D 2006 software (Correlated Solutions, Columbia, South Carolina).

The proximal end of each femur was then prepared for DIC compatibility. A layer of white paint was applied, followed by a black speckled pattern. The implanted femora were each placed into the testing machine and cycled ten times up to $1 \mathrm{kN}$ to bed-in the prosthesis being tested. Digital images were then obtained both at rest and with $1 \mathrm{kN}$ of compression. The images obtained were analysed using the above software. Each of the five prepared femora (designated A, B, C, D and E) were tested in this way with both prostheses. The remaining five control femora were also tested, giving 15 data sets in all. The medial cortex of the femur was under uniaxial compression. In the measured area the stress experienced was linearly related to the strain. Hence the measured variable for this study was the minimum principal strain. This was calculated from consecutive digital images using the Vic3D software, and detailed 2D contour maps were produced for each data set.

Statistical analysis. For statistical analysis, a line was superimposed on to the same part of each femur between the calcar and the medial cortex to just below the tip of the prosthesis. The minimum principal strain was calculated for 80 consecutive points along this line, which was divided into eight equal sections, designated 1 to 8 from the calcar distally, each containing ten data points of minimum principal strain values. The mean strain for each section was then determined for each of the femora A to E, and the means and SD for these eight sections calculated for both implants (Excel 2007 Microsoft, Redmond, Washington). The values obtained followed a parametric distribution, and therefore the mean values for each of the eight sections of the implanted femora were compared to those of the control femora using a two-tailed Student's unpaired $t$-test.

The p-value obtained for each section corresponded to the likelihood that the difference in the mean principal 

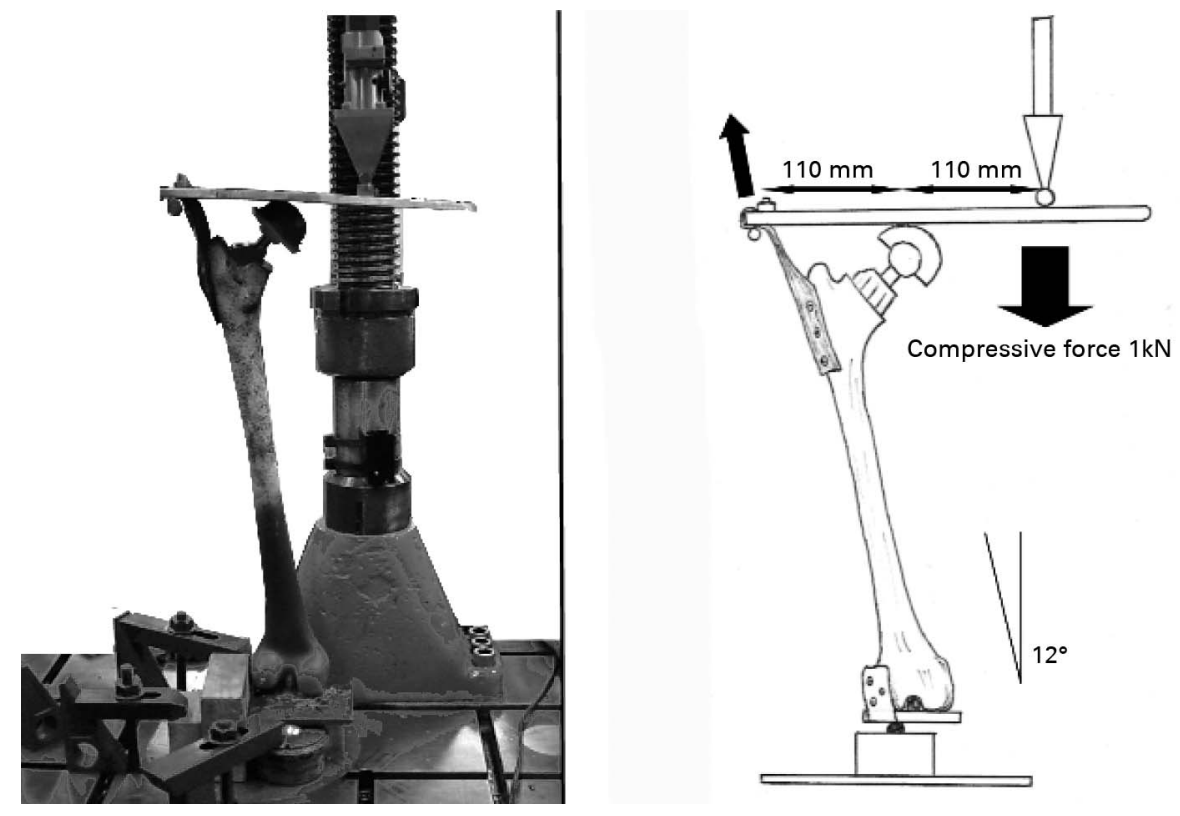

Fig. 2

Photograph and illustration of the entire construct within the testing machine, showing the femoral orientation.

strain for the implanted femur being compared to that of the control femur was due to chance. A p-value $<0.05$ was deemed to be statistically significant.

\section{Results}

Typical examples of the 2D strain maps obtained for the control and for the implanted femora are given in Figures 3 to 5 . In the control femur, the areas of highest strain on the medial side, corresponding to the light green and red areas, were found from a level just below the lesser trochanter distally for about $100 \mathrm{~mm}$. For the titanium implant there was a significant reduction in strain, indicating stress shielding, in all the measured areas $(\mathrm{p}<$ 0.05 ), but it was particularly marked at the calcar, corresponding to the darker blue and purple areas. For the CFRP implant there was again significant stress shielding around the calcar (sections 1 to $3: \mathrm{p}<0.03$ ) but distal to this the strains closely resembled those of the controls.

Table I shows the mean minimum principal strains and SD experienced by each section of both the control femora and those implanted with the titanium prosthesis. As can be seen, this implant produced a statistically significant reduction $(\mathrm{p}<0.05)$ in strain in all sections, ranging from approximately $55 \%$ at the calcar to $75 \%$ distally. Table II shows the same data, but for the CFRP prosthesis. There was a significant reduction in strain proximally in sections $1(\mathrm{p}=0.021)$ and $2(\mathrm{p}=0.002)$, but distal to this the strains were similar to those of the control femora, and in sections 4 to 7 ( $\mathrm{p}=0.715, \mathrm{p}=0.889$, $\mathrm{p}=0.9621, \mathrm{p}=0.404)$ there was no significant difference between the values obtained. These data are displayed in Figure 6.

\section{Discussion}

There was a significant reduction in the minimum principal strain in the proximal calcar (sections 1 and 2) with both implants. The proximal portion of the CFRP implant has a short core of titanium which is continuous with the neck. It would therefore be expected that in the proximal femoral sections the stress shielding behaviour of the implants would be similar owing to the discrepancy in stiffness between the implants and the surrounding bone, and this proved to be the case. This feature is not necessarily detrimental in either implant, however, it has previously been shown, that if an uncemented stem is very flexible proximally it causes movement between the stem and the bone which is likely to impair osseointegration. ${ }^{16} \mathrm{~A}$ more fruitful approach is to make the distal part of the stem as flexible as possible, and to tailor the stiffness of the proximal stem to optimise the load transfer to the surrounding bone. ${ }^{17}$

In femoral sections 3 to 7 , from the calcar to the medial cortex of the femur at the tip of the prosthesis, there was a significant reduction in the strain experienced in the femora containing the titanium implant compared to the controls. Again, this is as expected owing to the relatively high stiffness of this implant, which therefore takes a large share of the load from the femur. However, the strains experienced by the femora implanted with the CFRP prosthesis showed only a minor but significant reduction in section 3 , and between sections 4 and 7 were not significantly different from the control femora. This area is distal to the part of the prosthesis containing the titanium insert, where the modulus of elasticity is $13 \mathrm{GPa}$ to $20 \mathrm{GPa} .{ }^{18}$ It is this part that more readily deforms under load and thus transmits this strain to the surrounding bone (modulus $18 \mathrm{GPa}) .^{19}$ 

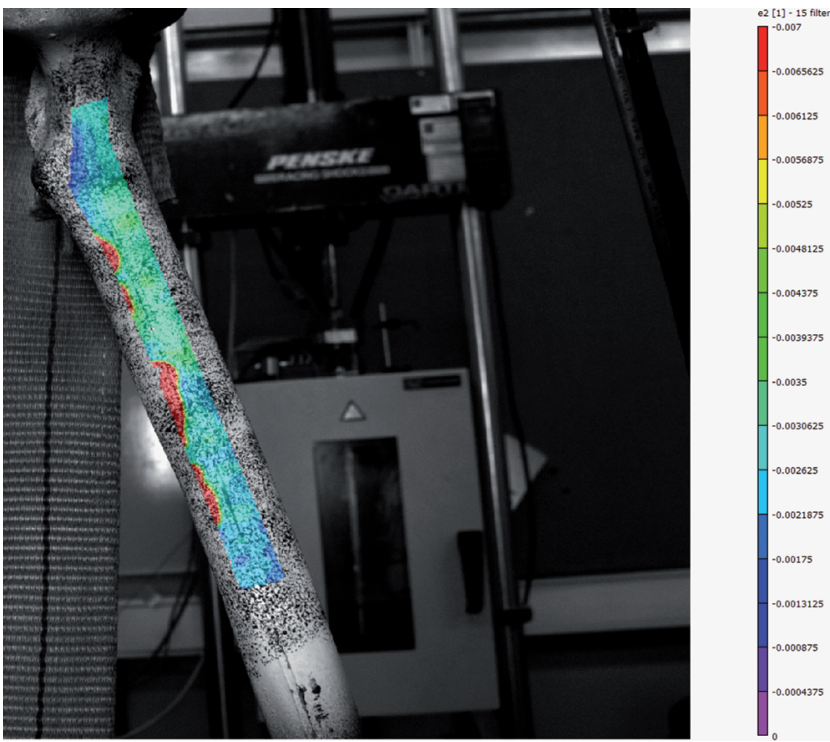

Fig. 3

Digital image of a control femur under $1 \mathrm{kN}$ load as viewed from the medial side. The head and calcar are in the upper left corner, with the medial surface of the shaft of the femur continuing inferiorly and to the right. A two-dimensional strain map of the area under study is superimposed on to the image, with minimising strain represented by a colour change from purple to red.
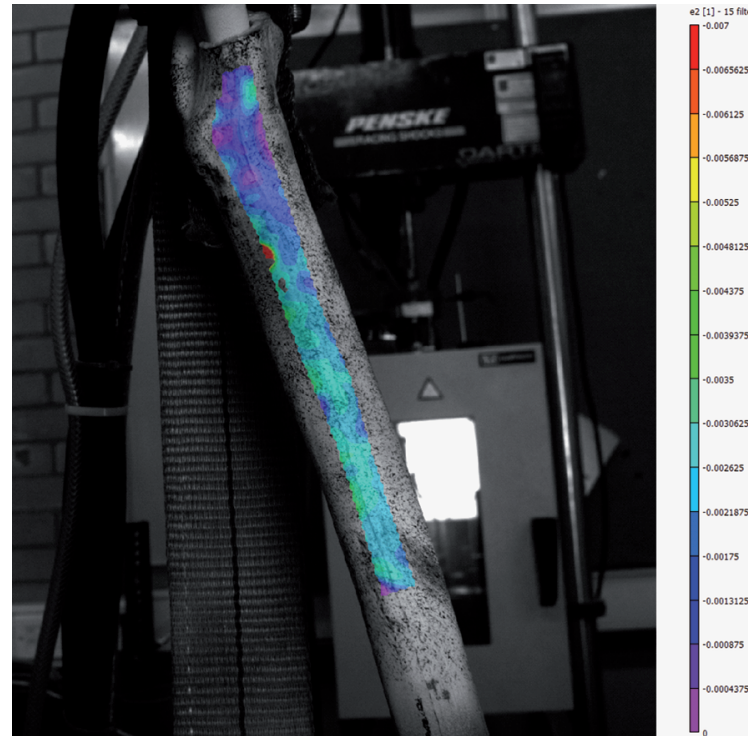

Fig. 4

Digital image of a femur implanted with the titanium implant under $1 \mathrm{kN}$ load. A two-dimentional strain map is superimposed on the image.

The strain values experienced in section 8 by all of the implanted femora showed small but statistically significant reductions compared to the controls. This area is beyond the tip of the prosthesis where the femur is bearing the full load, and therefore the presence of the implant would not significantly affect the modulus of elasticity of the femur at

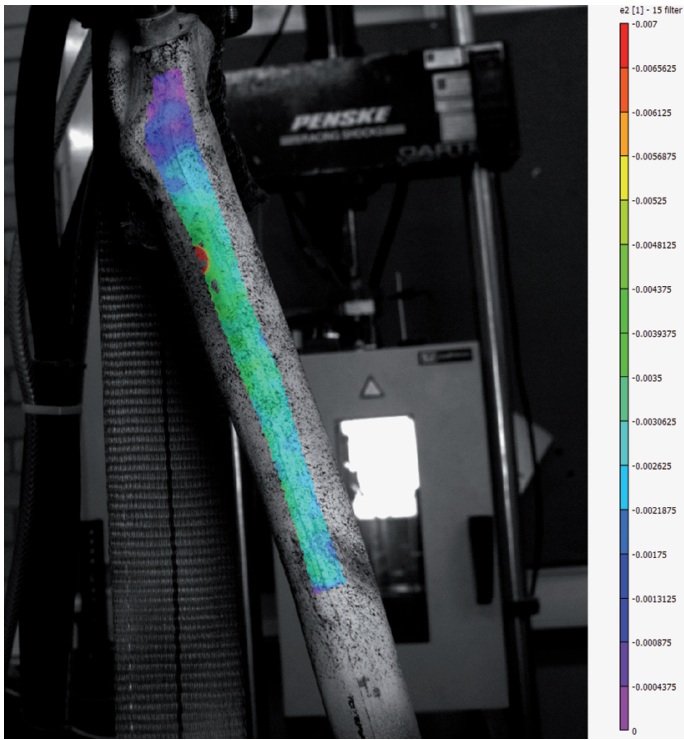

Fig. 5

Digital image of a femur implanted with the carbon-fibre reinforced plastic implant under $1 \mathrm{kN}$. A two-dimensional strain map is superimposed on the image. this point. It is not known why these reductions exist, but it is likely that the proximal changes in load distribution caused by the implants have changed the load distribution distally, possibly as a consequence of a cantilever effect.

Other similar experiments using alternative methods of strain measurement have yielded similar results. Otani et $\mathrm{al}^{4}$ and Akay and Aslan ${ }^{20}$ used strain gauges at different locations on the proximal part of implanted femora under load, and found that metallic implants caused significant stress shielding compared to composite stems. Vail et $\mathrm{al}^{9}$ used a photo-elastic technique to compare surface strains of human femora when implanted with titanium, carbon fibre and polymethylmethacrylate stems. They found that even though they all caused stress shielding in the calcar region, with decreasing stem modulus the effect distal to this was reduced.

Digital image correlation has been used before in orthopaedic research when investigating changes in the behaviour of bone during fracture healing, but a literature search revealed no published articles relating to its use in assessing strain transfer in hip prostheses. ${ }^{21}$ It is a simple, easily reproducible and extremely accurate technique which has allowed the production of detailed 2D strain maps of the medial side of the femur. As a result, visual comparisons can be made for whole areas, rather than just at solitary sites along a single line. Owing to the amount of data available in spreadsheet form, any statistical tests that are applied to investigate differences in strain for particular areas with differing implants are simple to perform on a wide scale, and consequently give highly significant results. 
Table I. The mean minimum principal strain values (SD) for each of the eight sections of the control femora and the five femora when implanted with the titanium prosthesis. The latter values are also displayed as percentages of the control group for each section

\begin{tabular}{|c|c|c|c|c|c|c|}
\hline $\begin{array}{l}\text { Section of } \\
\text { femur }\end{array}$ & $\begin{array}{l}\text { Mean minimum principal } \\
\text { strain (control femora) }\end{array}$ & Control femora & $\begin{array}{l}\text { Mean minimum principal } \\
\text { strain (titanium prosthesis) }\end{array}$ & Titanium prosthesis & $\begin{array}{l}\text { Percentage strain of } \\
\text { control group }(\%)\end{array}$ & $\begin{array}{l}\text { T-test against controls } \\
\text { (p) }\end{array}$ \\
\hline 1 & $-2.43 \mathrm{E}-03$ & $1.93 \mathrm{E}-04$ & $-1.40 \mathrm{E}-03$ & 7.89E-04 & 54 & 0.022 \\
\hline 2 & $-2.35 \mathrm{E}-03$ & $1.86 \mathrm{E}-04$ & $-1.36 \mathrm{E}-03$ & 8.17E-04 & 57 & 0.029 \\
\hline 3 & $-3.12 \mathrm{E}-03$ & $2.10 \mathrm{E}-04$ & $-1.67 \mathrm{E}-03$ & $6.53 \mathrm{E}-04$ & 53 & 0.001 \\
\hline 4 & $-3.28 \mathrm{E}-0.3$ & 2.47E-04 & $-2.27 \mathrm{E}-03$ & 4.75E-04 & 69 & 0.003 \\
\hline 5 & $-3.41 \mathrm{E}-03$ & $3.92 \mathrm{E}-04$ & $-2.39 \mathrm{E}-03$ & $2.15 E-04$ & 70 & 0.001 \\
\hline 6 & $-2.38 \mathrm{E}-03$ & $1.74 \mathrm{E}-04$ & $-2.60 \mathrm{E}-03$ & $3.69 E-04$ & 79 & 0.006 \\
\hline 7 & $-3.17 \mathrm{E}-03$ & $2.24 \mathrm{E}-04$ & $-2.47 \mathrm{E}-03$ & 4.69E-04 & 78 & 0.017 \\
\hline 8 & $-3.09 E-03$ & $2.15 \mathrm{E}-04$ & $-2.34 \mathrm{E}-03$ & 6.11E-04 & 76 & 0.033 \\
\hline
\end{tabular}

Table II. The mean minimum principal strain values (SD) for each of the eight sections of the five femora when implanted with the carbon fibre-reinforced plastic (CFRP) prosthesis. These values are also displayed as percentages of the control group for each section

\begin{tabular}{|c|c|c|c|c|}
\hline Section of femur & $\begin{array}{l}\text { Mean minimum principal strain } \\
\text { (CFRP prosthesis) }\end{array}$ & SD & $\begin{array}{l}\text { Percentage strain of control group } \\
(\%)\end{array}$ & $\begin{array}{l}T \text {-test against control } \\
\text { (p) }\end{array}$ \\
\hline 1 & $-1.25 \mathrm{E}-03$ & $9.03 \mathrm{E}-04$ & 52 & 0.021 \\
\hline 2 & $-1.63 E-03$ & 4.34E-04 & 69 & 0.002 \\
\hline 3 & $-2.66 \mathrm{E}-03$ & 3.13E-04 & 85 & 0.025 \\
\hline 4 & $-3.34 \mathrm{E}-03$ & $2.70 \mathrm{E}-04$ & 102 & $0.715\left(\mathrm{~ns}^{*}\right)$ \\
\hline 5 & $-3.44 \mathrm{E}-03$ & $3.12 \mathrm{E}-04$ & 101 & $0.889(\mathrm{~ns})$ \\
\hline 6 & $-3.29 \mathrm{E}-03$ & 3.11E-04 & 100 & 0.962 (ns) \\
\hline 7 & $-3.04 \mathrm{E}-03$ & $1.94 \mathrm{E}-04$ & 96 & 0.404 (ns) \\
\hline 8 & $-2.65 E-03$ & 2.47E-04 & 86 & 0.017 \\
\hline
\end{tabular}

This is therefore probably the most accurate study of this type undertaken so far, and thus the beneficial effects of the Bradley implant have now been accurately mapped and annotated statistically.

The strain experienced by the lateral cortex of the femur was not analysed. The attachment of the abductor strap to the greater trochanter and proximal part of the lateral femur meant that the imaging equipment was not able to visualise this part directly, and hence could not measure the strain. However, the medial calcar and cortex are the main load-bearing portions of the femur and the most important in terms of stress shielding. ${ }^{22}$

The concept of a flexible-stemmed prosthesis has not gained widespread uptake. There are no clinical data regarding the long-term outcome, and very limited information from the short- to medium-term. $\mathrm{Au}^{23}$ followed up 23 patients ( 25 hips) for a mean of 44.8 months and found that results were comparable to those of other cemented or uncemented prostheses, but the flexibility conferred no advantage with regard to bone resorption when compared radiologically. However, clinical trials by both Akhavan et $\mathrm{al}^{24}$ and Kärrholm et $\mathrm{al}^{25}$ have found beneficial effects when comparing flexible implants to metallic ones in terms of clinical outcome and bone density in the medium-term. These findings have also been backed up both radiologically and histologically in animal models. ${ }^{26}$

Clearly, the laboratory conditions in which this static experiment was undertaken do not reproduce the complex

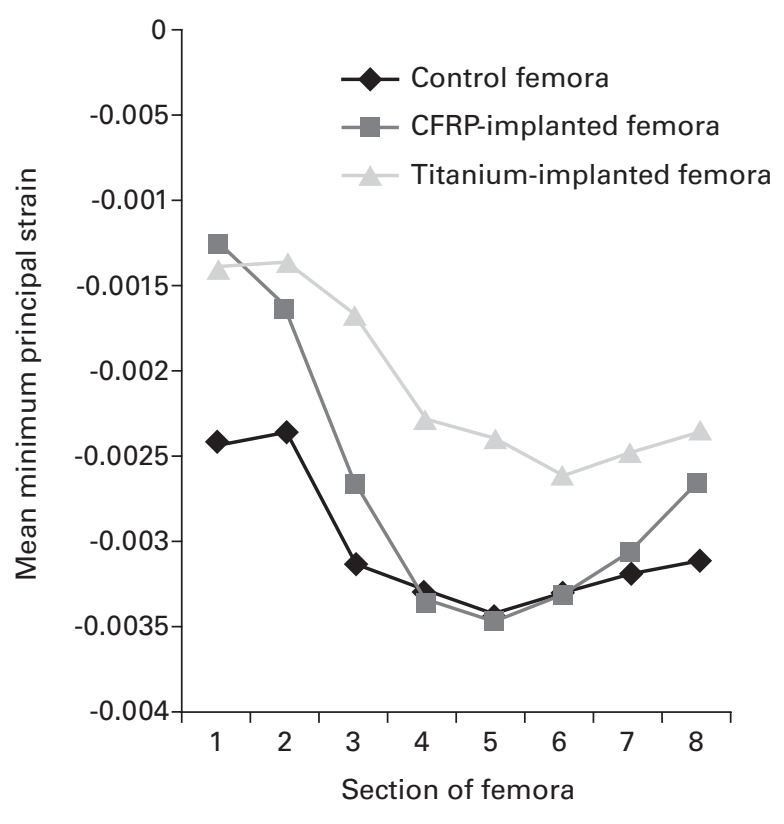

Fig. 6

Graph showing mean strains under load of the eight sections of the control femora compared with those of the implanted femora (CFRP, carbon fibre-reinforced plastic).

dynamic conditions to which a hip prosthesis is subjected in vivo. The abductor strap method has been used in similar experiments in an attempt to reproduce the tensile force 
provided by the abductor muscles. ${ }^{5,7,9}$ These muscles certainly contribute greatly to the forces acting on the femur, which have been calculated to be up to two to five times the compressive force on the femoral head. ${ }^{27}$

Whole femora with the condyles attached distally were also used, rather than just the proximal portion of the bone with a potted distal stump. This latter method has been used in various studies, but has been shown to significantly stiffen the experimental construct and hence to be less representative of the situation in vivo. ${ }^{5,28}$ The use of artificial femora is also not an ideal substitute for human bones. However. they have been tested biomechanically and shown to behave in a similar way to fresh cadaver femora. An absence of variation in both morphology and biomechanical properties between individual femora make them a good choice for use in studies requiring multiple samples for comparison. ${ }^{13}$ Also, the relative durability of these bones compared to cadaver femora meant that the implants could be interchanged in the same bone and a tight fit achieved each time. Thus, variables in strain distribution as a result of positioning of the implant were effectively excluded. ${ }^{29}$ However, this reflects most accurately the situation in vivo in the immediate post-operative period, when the implants are in the 'press fit' situation before osseointegration has occurred.

It was important that these implants were the same size and shape, as both of these features can affect the stiffness and hence the characteristics of stress shielding. Engh and Bobyn $^{30}$ showed that an increase in the diameter of the stem of a cobalt-chrome implant, and hence its stiffness, led to a decrease in the density of the bone on radiographs within two years, whereas Otani et $\mathrm{al}^{4}$ showed that a prosthesis with a collar may increase proximal femoral loading. More recently, emphasis has been placed on anatomically designed and custom-made implants. Østbyhaug et $\mathrm{al}^{5}$ performed a laboratory-based experiment comparing anatomical to custom-made stems and found that the latter caused less stress shielding.

The use of digital image correlation offers an excellent method of investigating strain distributions in bones in the laboratory. It provides detailed strain measurements covering the full field under investigation, and gives far more information than strain gauges. This study has shown that the strain distribution is very uneven, and that strain gauge measurements are highly sensitive to the exact position of the gauge. It confirms the beneficial effects of a flexible femoral stem in reducing stress shielding. Although the flexible composite stem used in this study had a significant bending stiffness, the amount of distal stress shielding that occurred was minimal. This is consistent with in vivo studies that have shown reduced bone resorption with more flexible femoral stems. ${ }^{24-26}$ This may have clinical implications with regard to periprosthetic bone remodelling and long-term maintenance of bone density, and hence a reduction in the risk of periprosthetic operative fracture.
No benefits in any form have been received or will be received from a commercial party related directly or indirectly to the subject of this article.

\section{References}

1. Rubash HE, Sinha RK, Shanbhag AS, Kim SY. Pathogenesis of bone loss after total hip arthroplasty. Orthop Clin North Am 1998;29:173-86.

2. Bugbee WD, Culpepper WJ 2nd, Engh CA Jr, Engh CA Sr. Long-term clinical consequences of stress-shielding after total hip arthroplasty without cement. J Bone Joint Surg [Am] 1997;79-A:1007-12

3. Nagels J, Stokdijk M, Rozing PM. Stress shielding and bone resorption in shoulder arthroplasty. J Shoulder Elbow Surg 2003;12:35-9.

4. Otani T, Whiteside LA, White SE. Strain distribution in the proximal femur with flexible composite and metallic femoral components under axial and torsional loads. J Biomed Mater Res 1993;27:575-85.

5. Østbyhaug PO, Klaksvik J, Romundstad P, Aamodt A. An in vitro study of the strain distribution in human femora with anatomical and customised femoral stems. J Bone Joint Surg [Br]2009;91-B:676-82.

6. Maistrelli GL, Fornasier V Binnington A et al. Effect of stem modulus in a total hip arthroplasty model. J Bone Joint Surg [Br] 1991;73-B:43-6.

7. Decking R, Puhl W, Simon U, Claes LE. Changes in strain distribution of loaded proximal femora caused by different types of cementless femoral stems. Clin Biomech (Bristol, Avon) 2006;21:495-501

8. Morscher $\mathbf{E}$, Mathys $\mathbf{R}$. La prothèse totale isoélastique de hanche fixée sans ciment. Acta Orthop Belg 1974;40:639-47 (in French).

9. Vail TP, Glisson RR, Koukoubis TD, Guilak F. The effect of hip stem material modulus on surface strain in human femora. J Biomech 1998;31:619-28.

10. Huiskes R, Weinans H, van Rietbergen B. The relationship between stress shielding and bone resorption around total hip stems and the effects of flexible materials. Clin Orthop 1992;274:124-34

11. Sharpe WN, Pulskamp J, Gianola DS, et al. Strain measurements of silicon dioxide microspecimens by digital imaging processing. Experimental Mechanics 2007;47:649-58.

12. Chen DJ, Chiang FP. Computer-aided speckle interferometry using spectral amplitude fringes. Appl Opt 1985;32:225-36.

13. Cristofolini L, Viceconti M, Cappello A, Toni A. Mechanical validation of whole bone composite femur models. J Biomech 1996;29:525-35.

14. Hua J, Walker PS. Relative motion of hip stems under load: an in vitro study of symmetrical, asymmetrical, and custom asymmetrical designs. J Bone Joint Surg [Am] 1994;76A:95-103.

15. McLeish RD, Charnley J. Abduction forces in the one-legged stance. J Biomech 1970;3:191-209.

16. Morscher EW, Dick W. Cementless fixation of "isoelastic" hip endoprostheses manufactured from plastic materials. Clin Orthop 1983;176:77-87.

17. Evans SL, Gregson PJ. Numerical optimization of the design of a coated, cementless hip prosthesis. J Mater Sci Mater Med 1994;5:507-10.

18. Jones DP, Leach DC, Moore DR. Mechanical properties of poly(ether-ether-ketone) for engineering applications. Polymer 1985;26:1385-93.

19. Reilly DT, Burstein AH, Frankel VH. The elastic modulus for bone. J Biomech 1974;7:271-5.

20. Akay M, Aslan N. Numerical and experimental stress analysis of a polymeric composite hip joint prosthesis. J Biomed Mater Res 1996;31:167-82.

21. Thompson MS, Schell H, Lienau J, Duda GN. Digital image correlation: a technique for determining local mechanical conditions within early bone callus. Med Eng Phys 2007;29:820-3.

22. Oh I, Harris WH. Proximal strain distribution in the loaded femur: an in vitro comparison of the distributions in the intact femur and after insertion of different hip-replacement femoral components. J Bone Joint Surg [Am] 1978;60-A:75-85

23. Au MK. Isoelastic total hip replacement: clinical evaluation of prosthetic isoelasticity. $J$ Formos Med Assoc 1994;93:497-502.

24. Akhavan S, Matthiesen MM, Schulte L, et al. Clinical and histologic results related to a low-modulus composite total hip replacement stem. J Bone Joint Surg [Am] 2006;88A:1308-14.

25. Kärrholm J, Anderberg C, Snorrason F, et al. Evaluation of a femoral stem with reduced stiffness: a randomized study with use of radiostereometry and bone densitometry. J Bone Joint Surg [Am] 2002;84-A:1651-8.

26. Maistrelli GL, Fornasier V, Binnington A, et al. Effect of stem modulus in a total hip arthroplasty model. J Bone Joint Surg [Br] 1991;73-B:43-6.

27. Cristofolini L, Viceconti M, Toni A, Giunti A. Influence of thigh muscles on the axial strains in a proximal femur during early stance in gait. J Biomech 1995;28:617-24.

28. Phillips ATM. The femur as a musculo-skeletal construct: a free boundary condition modelling approach. Med Eng Phys 2009;31:673-80.

29. Jasty M, O'Connor DO, Henshaw RM, Harrigan TP, Harris WH. Fit of the uncemented femoral component and the use of cement influence the strain transfer the femoral cortex. J Orthop Res 1994;12:648-56.

30. Engh CA, Bobyn JD. The influence of stem size and extent of porous coating on femoral bone resorption after primary cementless hip arthroplasty. Clin Orthop 1988:231:7-18. 